\title{
Rethinking Media Richness: Towards a Theory of Media Synchronicity
}

\author{
Alan R. Dennis \\ Terry College of Business \\ University of Georgia, Athens, GA 30602 \\ adennis@uga.edu
}

\author{
Joseph S. Valacich \\ College of Business and Economics \\ Washington State University, Pullman WA 99164 \\ jsv@mail.wsu.edu
}

\begin{abstract}
This paper describes a new theory called a theory of media synchronicity which proposes that a set of five media capabilities are important to group work, and that all tasks are composed of two fundamental communication processes (conveyance and convergence). Communication effectiveness is influenced by matching the media capabilities to the needs of the fundamental communication processes, not aggregate collections of these processes (i.e., tasks) as proposed by media richness theory. The theory also proposes that the relationships between communication processes and media capabilities will vary between established and newly formed groups, and will change over time.
\end{abstract}

\section{Introduction}

One of the most widely applied theories of media use is media richness theory. Media richness theory argues that task performance will be improved when task needs are matched to a medium's richness -- "the ability of [its] information to change understanding within a time interval" [6, p. 560]. Daft and Lengel argue that media capable of sending "rich" information (e.g., face-to-face meetings) are better suited to equivocal tasks (where there are multiple interpretations for available information), while media that are less "rich" (e.g., computer-mediated communication) are best suited to tasks of uncertainty (where there is a lack of information). However, empirical tests of media richness theory have not been terribly convincing, particularly for "new media" such as computer mediated communication [e.g., 7, 10, 11, 19, $24,29,39,50,59]$. The question, is should we continue to pursue media richness theory, attempting to refine it to

\footnotetext{
${ }^{1}$ The authors would like to thank Ron Rice and Brad Wheeler for particularity helpful comments in refining some of the concepts in this paper. We would also like to thank Allen Lee and Lynne Markus for sharing working papers that aided in the development of our ideas. Both authors contributed equally to this work; JSV lost the first-author coin toss.
}

compensate for the weak findings and draw new conclusions based on the enhancements, or should we attempt formulate a new theory [e.g., 34, 35, 41]?

In this paper, we take the second approach. We propose a new theory, which we call a theory of media synchronicity. The theory proposes that group communication processes, regardless of task outcome objectives, are composed of two primary processes, conveyance and convergence. The theory also proposes that media have a set of capabilities that play a dominant role when addressing each type of communication process. Performance will be enhanced when media capabilities are aligned with these processes.

\section{Rethinking Media Richness Theory}

\section{Media Richness Theory}

Media richness theory (a.k.a. information richness theory) proposes that task performance will be improved when task needs are matched to a medium's ability to convey information [6]. Daft and colleagues [6, 7, 9] argued that media varied in their ability to enable users to communicate and change understanding -- their "richness." Richer media were those with a greater language variety (the ability to convey natural language rather than just numeric information), a greater multiplicity of cues (the number of ways in which information could be communicated such as the tone of voice), a greater personalization (ability to personalize the message), and more rapid feedback.

Media richness theory [6, 7] argues that certain media are better able to transmit information depending upon whether the information is used in situations of uncertainty or equivocality. Uncertainty exists when a framework for interpreting a message is available, but there is a lack of information to process (i.e., there are well understood predetermined responses to potential problems [8]). Equivocality exists when there are multiple (and possibly conflicting) interpretations for the information or the framework with which to interpret it. Equivocality requires negotiation among members to 
converge to consensus on one interpretation. Media providing higher richness are preferred. In contrast, uncertainty requires someone in the group to provide, locate, or create the needed information; leaner media are preferred. In short, Daft and Lengel [6] argue that media capable of sending "rich" information are better suited to equivocal tasks, while those that are less "rich" are best suited to tasks of uncertainty. However, research suggests that the degree of media richness may be relatively unimportant for reducing uncertainty [see 46].

Most tests of media richness theory have examined perceptions of media fit, not actual effects of media use [10]. Typically, managers have been asked to choose a medium to send a set of hypothetical messages to determine whether their choices fit the predictions of media richness theory [e.g., 7, 11, 25, 50, 58, 59]. Researchers have concluded that media choice is affected by factors beyond richness [12, 18, 28, 46, 49, 50, 69].

However, media richness theory was developed to not theorize how managers choose media, but to theorize which media should prove most effective in what situations $[6,10]$. In other words, does the use of richer (leaner) media improve the performance of equivocal (uncertain) tasks? Initial evidence has not been very supportive. The overall pattern of results across five empirical studies of media use run counter to the predictions of media richness theory $[2,10,19,61,62]$.

\section{Beyond Media Richness}

Many of Daft and Lengel's [6] media richness dimensions owe their origins to social presence theory [55] and thus, much of media richness theory is built on the presumption that increased richness is linked to increased social presence [69] ${ }^{2}$. One primary thesis of this paper is that the richness of a medium -- its ability to change understanding within a time interval -- is linked not only to its social factors but also to its information processing capabilities. In this section, we present a set of media characteristics that we believe are important in understanding the effects of media use on the ability to communicate and process information [see also 45,51 ].

For communication to be successful, the receiver must understand the message that sender intended to send, and both the sender and receiver must agree that the receiver has understood the message [5]. One of the oldest and most pervasive theories of communication was first

\footnotetext{
2 Another perspective has suggested that the richness of media -- electronic media in particular -- may be partially socially defined [12 52]. This means that group and organizational experiences and norms, as well as knowledge of the sender [57] can alter participants' perceptions of media richness. Media that are "lean" to one group, may be "richer" to another, and these perceptions may change over time [33]. Research by Rice and colleagues, however, concludes that social factors to have only minor effects on media richness perceptions [47, 48, 49].
}

proposed by Shannon and Weaver [53]. It has been criticized for its narrow focus [e.g., 3, 43] and other theories have attempted to improve it [e.g., 1] but it has endured for 50 years. The Shannon-Weaver theory argues that the transmission of a message begins with the source of the message who encodes the message for transmission over a channel using a transmitter. The channel carries the message to a receiver, which the destination uses to decode the message.

In our terminology, the source and destination are people (sender and receiver, respectively) and the transmitter, channel, and receiver are parts of the medium through which they communicate. We believe that five media characteristics can affect communication.

Imme diacy of feedback. Immediacy of feedback is the extent to which a medium enables users to give rapid feedback on the communications they receive $[6,9]$. It is the ability of the medium to support rapid bidirectional communication.

Symbol variety. Symbol variety is the number of ways in which information can be communicated -- the "height" of the medium -- and subsumes Daft and Lengel's multiplicity of cues and language variety. The essence of communication and language is symbols [26]. There are at least four distinct ways in which symbol variety may affect the communication and understanding of messages. First, some information may be easier to convey in one format rather than another. Second, verbal and nonverbal symbols enable senders to include information beyond the words themselves when the message is transmitted. Third, the cost to compose a message or to process an incoming message using some symbol set may impose a delay cost [44] or a production cost [4] that alters the way in which the sender creates messages or reduces the understanding of the receiver. Finally, the lack of verbal and non-verbal symbols can have significant effects on social perceptions [68]. In general, when verbal and non-verbal symbols are removed there is a loss of social presence [55, 47], such that the people with whom one is communicating become less like real people and more like objects [68].

Parallelism. This refers to the number of simultaneous conversations that can exist effectively -the "width" of the medium [62; cf. multiple addressability: 45, 56]. In traditional media such as the telephone, only one conversation can effectively use the medium at one time. In contrast, many electronic media can be structured to enable many simultaneous conversations to occur. However, as the number of conversations increase, it becomes increasingly difficult to monitor and coordinate the conversations [41].

Rehearsability. Rehearsability is the extent to which the media enables the sender to rehearse or fine tune the message before sending [cf. editability: 45]. Some media enable the sender to carefully edit a message 
while it is being sent to ensure that the intended meaning is expressed exactly, with no extraneous information.

Reprocessability. Reprocessability is the extent to which a message can be reexamined or processed again within the context of the communication event [cf. 45; externally recorded memory: 56].

Conclusions about me dia richness. Table 1 examines the capabilities of several media. In several cases, media are listed as having a range of capabilities because they are configurable. For example, written mail sometimes enables the use of tables or graphics. The same may be said for face-to-face communication because it may or may not be possible to include tables, graphics, pictures, and full motion video in a face-to-face conversation (as it would be with e-mail attachments for example).

This table suggests three important conclusions beyond those of media richness theory. First, no one medium has the highest values on all dimensions so none could be labeled as "richest" in Daft \& Lengel's [6] terms. Second, media are not monolithic. It is possible for one medium to possess different levels of a communication capability depending upon how it is configured and used (e.g., one electronic mail system may have a limited symbol variety (text only), while another includes graphics, and video). Third, ranking media in absolute terms is not practical. Daft and Lengel [6] argued that media can be ranked in order of their richness without consideration of context [see also 24]. Media possess many capabilities, each of which may be more or less important in a given situation. The "richest" medium is that which best provides the set of capabilities needed by the situation: the individuals, task, and social context within which they interact. Thus, concluding that face-to-face communication is the "richest" media is inappropriate.

\section{Beyond Task}

"Task" has been a key element in media richness theories. In this section, we argue that regardless of the task (whether equivocal or uncertain), groups and the individuals within them perform a similar set of fundamental micro-level communication processes. We believe that attempting to recommend a single "best" medium based on a high level task is doomed to failure.

TIP Theory. TIP theory -- Time, Interaction, and Performance -- argues that groups are embedded into surrounding social and organizational systems and as a result perform three simultaneous functions as they work $[31,32]$. The first is the production function (i.e., performing the assigned task), which makes contributions to the organizations within which they are embedded (e.g., solve a problem, or exploit a new opportunity). The second is group well-being, which makes contributions to the group itself as an intact and continuing social structure (e.g., members assume roles and develop behavior norms). The third is member-support, which makes contributions to the individual members (e.g., relationships with others).

Within these three functions (production, group well-being, or member support), TIP theory [32] argues that groups can be engaged in any of four modes: inception, technical problem solving, conflict resolution, and execution (which is similar to Tuckman's [60] forming, storming, norming, and performing).

Inception refers to the selection of project goals, and for the individual members, which naturally occurs early on in the group's life, but may reoccur when the task, group, or members change, and require the group to rethink goals [cf. 15]. Technical problem solving involves resolving technical issues about how the project will be accomplished, staffing, and roles issues (i.e., who does what, when, how, and with whom, means choice). Conflict resolution is the process of resolving conflicting preferences, values, interests, work assignments, and rewards (i.e., preference resolution). Execution refers to the set of behaviors necessary to carry out the goals of the project, group, or individual members (i.e., doing the work). Execution often is performed by individuals or sub-groups acting separately without the entire group.

There is no inherent order or required path to these modes, except that all projects, at a minimum, move

Table 1. Relative Trait Salience of Selected Media

\begin{tabular}{|l|c|c|c|c|c|}
\hline & Feedback & $\begin{array}{l}\text { Symbol } \\
\text { Variety }\end{array}$ & Parallelism & Rehearsability & Reprocessability \\
\hline Face-to-face & high & low-high & low & low & low \\
\hline Video conference & medium-high & low-high & low & low & low \\
\hline Telephone & medium & low & low & low & low \\
\hline Written mail & low & low-medium & high & high & high \\
\hline Voice mail & low & low & low & low-medium & high \\
\hline Electronic mail & low-medium & low-high & medium & high & high \\
\hline Electronic phone ("chat") & medium & low-medium & medium & low-medium & low-medium \\
\hline Asynchronous groupware & low & low-high & high & high & high \\
\hline Synchronous groupware & low-medium & low-high & high & medium-high & high \\
\hline
\end{tabular}


through inception and execution in the production function. Projects could start in the inception mode, move to execution, discover some new information, and move to the technical problem solving or conflict resolution modes, and so on. It is also important to recognize that groups may be in different modes in different functions (e.g., problem-solving in the production function, and execution in group well-being and member support).

Tasks of equivocality. Using the task terminology of media richness theory [6], suppose that a group has just undertaken a high equivocality task. What do they do? The group begins in a mode of inception: the group must come to a shared agreement on goals for the assigned task (i.e., the production function). With high equivocality, there are multiple and possibly conflicting interpretations of the situation. "Participants are not certain about what questions to ask, and if questions are posed, the situation is ill-defined to the point where a clear answer will not be forthcoming" [6, pp. 556-557]. There is no understanding of outcome preferences and the cause-effect links of various options [65]. Resolving this equivocality (or "confusion") requires sensemaking: negotiation and construction of a mutually shared agreement on the causal linkages and desired outcomes -- in essence, "framing" the situation [64]. Inception (defining goals) is the first step of this in the production function.

There are five basic sensemaking strategies that a group can adopt to reduce equivocality [64, 65]. One strategy is action: members ask questions of or propose actions, information or opinions to other group members, and await the response. A second is triangulation, seeking information in a variety of formats (e.g., quantitative, qualitative, graphical) from a variety of sources (e.g., other group members, other departments, other organizations, national databases) because any one type or source of information may be inaccurate or present an incomplete picture. A third strategy is contextualization, the connection of the new events to past events (e.g., "this is like the situation faced by company X last year"). A fourth strategy is deliberation, the slow and careful reasoning required to induce plausible patterns from the information gained through action, triangulation, and contextualization. When this reasoning is allowed to incubate, meaning becomes clearer; when information comes too quickly and immediate responses are required, individuals fail to process information and fall back on habitual processes and stereotypes. The final strategy is affiliation, seeking to understand how other individuals interpret or understand information, and coming to a mutually agreed upon meaning.

Thus for the first step of resolving equivocality in setting goals, the first three sensemaking strategies (action, triangulation, contextualization) share the same fundamental communication process: the conveyance of information. The conveyance of information focuses on the dissemination of a diversity of information from many sources, information not previously known to participants. The goal is to disseminate and obtain as much relevant information as possible to aid in understanding the situation. However, conveyance has little value without the fourth sensemaking strategy, deliberation -- making sense of and integrating the information to derive meaning for the current situation.

Once information is shared through conveyance processes, the fifth sensemaking strategy (affiliation) requires a second fundamental communication process: the convergence on a shared meaning of this information. The focus here is on understanding each individual's interpretation of the information, not the information itself. The goal is to agree on the meaning of the information to current situation, which requires individuals to reach a common understanding and to mutually agree that they have achieved this understanding (or to agree that common understanding is not possible). This process examines ascribed meanings and conclusions drawn from a diverse set of information already known. This set of "distilled" information is generally a smaller than the original set of information because there is likely some overlap and similarity in conclusions drawn by the individuals. Convergence uses a comparison process in which individual compare their conclusions to those of others, rather than reexamining the entire information set [37]. Even with differences in conclusions, there is a reasonable chance that the different interpretations will have already been considered and thus the information will have been processed to a greater extent than the initial information on which deliberation is still needed. Thus assessing individual opinions usually requires less cognitive effort than assessing unprocessed factual information [40].

The key point is that for resolving equivocality, there are two fundamental communication processes (conveying information/deliberation and converging on a shared interpretation). Media richness theories emphasize the need to converge; conveyance is left to tasks of uncertainty. We argue that conveying information and converging on a shared meaning are equally critical for tasks of equivocality and uncertainty. Without adequate conveyance of information, individuals will reach incorrect conclusions. Without adequate convergence, the group cannot move forward.

The other three modes in production beyond inception (technical problem solving, conflict resolution, and execution) follow the same pattern. For example, technical problem solving is initiated if choosing how the task will be undertaken is the goal. To successfully complete technical problem solving, groups must convey 
information and converge on its meaning in order to move forward. Likewise, for different group functions -production, member support, group well-being -- groups will follow a similar pattern of conveyance and convergence. For example, group well-being concerns the relationships among members, such as their roles in the group, who does what, and what power and status members accrue. If members have well-established roles, group will usually briefly re-accept those during inception and move directly to execution [13]. If the group is newly formed or the task is so equivocal that traditional roles prove unworkable, members must choose new roles. To achieve this, groups will perform the same fundamental communication processes of information conveyance and convergence, plus deliberation, in order to move forward.

Tasks of uncertainty. Again using the task terminology of media richness theory, for tasks of uncertainty (or low equivocality tasks) there is a well defined framework, or the task is analyzable, but there is a lack of information. To solve this task, groups will follow the same basic modes as before, but the emphasis may be different. For the production function, project inception may be short, as goals may be clearly stated or readily deduced. Members will still have to convey information, deliberate, and converge on a shared set of goals, but the volume and degree of complexity will be less. Likewise, technical problem solving may be specified or readily deduced, so that members can move quickly to execution, whose focus is on the exchange of the information. Nonetheless convergence is required before the group can move to execution.

Group well-being and member support is less clear for tasks of uncertainty. For a well established group, the group may quickly proceed from inception to execution using habitual routines [13]. However, if the group is newly formed, or new members have been added to the group, more time may need to be spent in inception, technical problem solving, and conflict resolution [15]. Nonetheless, the group will still use the fundamental processes of information conveyance and convergence, but the information may require a different symbol set.

\section{A Theory of Media Synchronicity}

Synchronous activity is that which moves at the same rate and exactly together [42]. Media synchronicity is the extent to which individuals work together on the same activity at the same time; i.e., have a shared focus. The first step is to examine the ability of the media capabilities (immediacy of feedback, symbol variety, parallelism, reprocessability, and rehearsability) to support the two communication processes (conveyance and convergence) across the three group functions (production, group well-being, and member support). See Figure 1.

We have argued that all tasks are composed of two fundamental communication processes, conveyance and convergence. Conveyance is the exchange of information, followed by deliberation on its meaning. It can be divergent, in that not all participants need to focus on the same information at the same time, nor must they must agree on its meaning. In general, low media synchronicity is preferred for conveyance.

Convergence is the development of shared meaning for information. By definition it is convergent, in that participants strive to agree on the meaning of information and agree that they have agreed. This means that participants must understand each other's views. In general, high synchronicity is preferred for convergence.

\section{Media Capabilities \& Communication Processes}

Symbol variety. The importance of symbol variety depends upon the information that needs to be communicated. It is best thought of as a "hygiene factor" in the terminology of Herzberg et al. [14] in that there is nothing inherently important or satisfying about the symbol variety of the medium. However, if the medium does not provide a particular symbol set when it is needed, then it interferes with work and individuals become quickly dissatisfied (e.g., one has a straightedged screwdriver when a Philips-head is required).

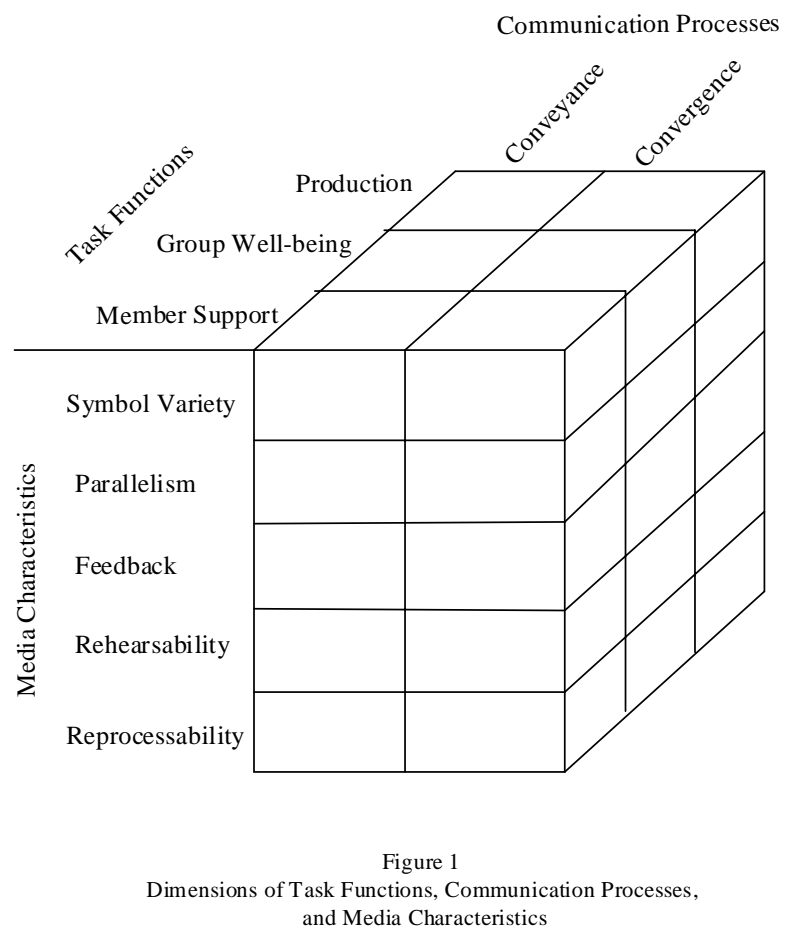


In general, for the production function, conveyance should require a greater symbol variety depending upon the task. While some tasks may have only simple information requirements, others may benefit from tables, graphics, full motion video, etc. In contrast, convergence in the production function requires understanding others' interpretations; something than can usually be communicated using a simpler symbol set. In situations where individuals cannot or are less comfortable conveying their opinions directly, verbal and nonverbal symbols (e.g., vocal tone, gestures) may become important (e.g., negotiation, interactions between superiors and subordinates). Assuming that all parties wish to communicate (a major assumption), we believe these symbols are less important. See Figure 2.

Conveyance and convergence for group well-being and member support are likely to also require simple symbols sets, but possibly slightly different ones. These

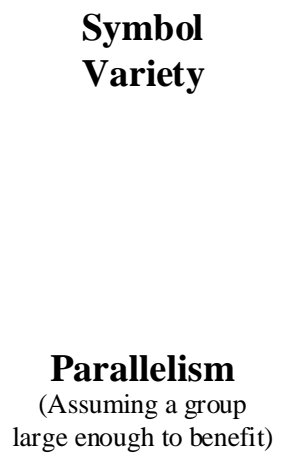

Feedback

(Assuming a large amount of information requiring deliberation is conveyed)

Reprocessability (Assuming a large amount of information requiring deliberation is conveyed)
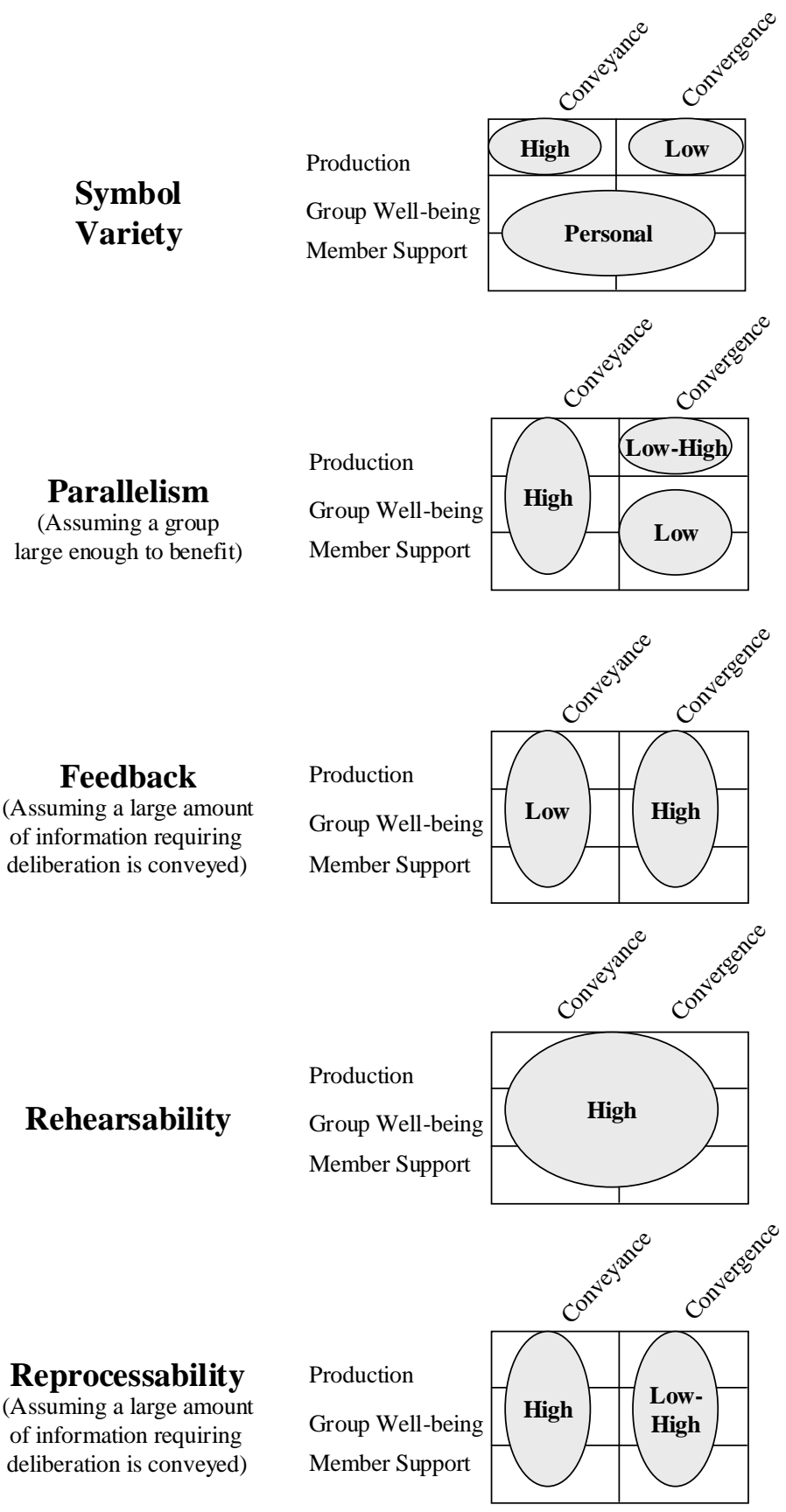

Figure 2: Desired Media Characteristics 
tasks may require symbols to express personal feelings and emotion, making verbal and nonverbal symbol sets more important [55], yet some groups have shown strong abilities to communicate emotion and feelings without the use of verbal and nonverbal symbols [66, 67]. Established groups whose members have more shared experiences likely will have less need for verbal and nonverbal symbol sets than newly formed groups whose members have less knowledge of each other [12, 52]. Likewise, groups whose members engage in group wellbeing and member support outside of the formal group interactions will have less need for these symbols.

Parallelism. The importance of parallelism depends upon the number of participants [38]. Parallelism is unimportant for small groups. For large groups, however, parallelism is very important to conveyance in enabling all members to participate (regardless of whether the function is production, group well-being or member support). In general, convergence will benefit from low parallelism, because the goal is to understand each individual member's viewpoints. It is difficult to monitor and coordinate the many separate conversations enabled by parallelism, and to engage in comparisons and develop mutual understanding from them; in this case, parallelism introduces noise. The exception to this is when there is a framework for integrating individuals' understandings and a voting structure is used [e.g., 63], which is more likely to occur in the production function than for the group well-being or member support functions.

Feedback. The immediacy of feedback is important in improving understanding because enables mid-course corrections in message transmission so that any misleading elements in the message as sent can be quickly corrected. As noted above, more immediate feedback can have significant benefits in improving the speed and accuracy of communication. However, it presents two problems. First, it comes at a high cost; the sender and receiver(s) must interact synchronously, and scheduling a single time to interact can require significant effort in some circumstances. Second, media that enable rapid feedback create expectations for rapid feedback that can interfere with communication. For example, face-to-face communication requires rapid feedback interfering with deliberation, encouraging premature action [65].

We conclude that for conveyance of information that requires deliberation (e.g., large volumes of information, complex or equivocal information), rapid feedback may impair performance. As argued above, convergence requires less information and less cognitive effort than the deliberation required for the initial conveyance of information, and thus rapid feedback may interfere to a lesser extent than for conveyance. Since the goal is to understand other's interpretations of information, not the information itself, feedback becomes important.

Rehearsability. Rehearsability enables the sender to compose a message with the exact meaning that he or she intends. It is probably unimportant for simple messages, but becomes more important as the complexity or equivocality of the message increases because increased rehearsability will lead to improved understanding. However, media with high rehearsability tend to have lower feedback.

Reprocessability. Reprocessability enables the receiver to repeatedly process the message to ensure that he or she accurately understands the message as delivered (which may or may not be the message the sender intended to send), and, most importantly, enables deliberation. Reprocessability becomes more important as the volume, complexity, or equivocality of the message increases. Increased reprocessability will lead to improved understanding regardless of the information or communication process (conveyance or convergence) but is often more important to conveyance. Conveyance often produces information requiring deliberation, and reprocessability is important to deliberation.

Summary. Communication environments that support high immediacy of feedback and low parallelism encourage the synchronicity that is key to the convergence process. Communication environments that support low immediacy of feedback and high parallelism provide the low synchronicity that is key to the conveyance/deliberation process. Symbol variety is related to the nature of information under discussion and thus little can be said in general for its relationship to convergence versus conveyance processes. Both conveyance and convergence should benefit from higher levels of rehearsability, but often it moves in opposite directions to the immediacy of feedback. Reprocessability is important for the deliberation that follows conveyance, but can also be important for convergence when deliberation in needed. Therefore:

P1: For group communication processes in which convergence is the goal, use of media providing high synchronicity (high feedback and low parallelism) will lead to better performance.

P2: For group communication processes in which conveyance is the goal, use of media providing low synchronicity (low feedback and high parallelism) will lead to better performance.

P3: A medium's symbol variety will only affect performance when a needed symbol set is not available.

P4: Use of media provided higher rehearsability will lead to better performance.

P5: For group communication processes in which conveyance is the goal, use of media providing higher reprocessability will lead to better performance. 


\section{Group Development}

There are likely several situational factors that will influence the extent to which a given communication environment will be effective for different groups, even those performing similar tasks. One factor is the extent to which groups have worked together in the past.

Established groups. Established groups are more likely to have established norms for member support and group well-being (e.g., roles within the group), and well established processing norms for the production function [13]. When the task is routine, it is more likely that norms will simply be re-applied to the task. The group will be more likely to move directly to execution with less problem solving and conflict resolution.

During the execution mode, members are better able to work separately on their assigned tasks [32]. Execution requires more conveyance than convergence, although some convergence is clearly required. The need for media synchronicity is therefore lower during execution than during inception, technical problem solving, and, especially, conflict resolution. However, when faced with a non-routine task that has little resemblance to past tasks, established groups may need more time in inception and problem solving in the production function, and thus require more convergence.

As a group matures they "are likely to become able to carry out all their functions, at least for routine projects, with much less rich information exchanges" [34, p. 95]. This means that the communication requirements of groups will likely differ over time, depending upon shared experiences [12, 52]. Perceptions about a medium's usefulness for a task and the group's ability to perform a task in a given medium changes over time [15]. The interplay of a group's increased experience and the its development of standards and norms, are likely to interact and result in relatively improved task performance over time. It is therefore probable that as group members come to know each other better over time, they share common experiences that may be evoked by very simple messages that refer to those shared experiences. In Weick's [64] terminology, contextualization becomes easier. This suggests that more experienced groups will require less convergence communication processes. For a given group over time, they should rely less on convergence processes. Thus:

P6: Established groups with accepted norms will require

less use of media with high synchronicity (high feedback and low parallelism) than groups without such norms.

P7: As a given group works and develops over time, it will require less use of media with high synchronicity (high feedback and low parallelism).

Newly formed groups. Newly formed groups will have fewer well established norms and will likely spend more time in inception, technical problem solving, and conflict resolution for all three functions (production, group well-being and member support) establishing task-related norms, roles and individual activity levels. This will result in more complex processes requiring more conveyance, and, especially, convergence.

Groups will likely follow different sequences of task focused and socially focused activities. In some instances a group's primary goals may not be production, but be focused on member support and group well-being activities. TIP theory predicts that the functions and activities of the group change over time as the group moves into different states of more socially focused or more task focused activities. This implies that the dominant communication processes may be those that encourage socially focused activities [see 34], which may not be the same as those needed for performing task activities. While groups may shift between task activities and social activities at any point, research in group development suggests that initial meetings of new groups often focus first on social processes rather than task processes [32, 36, 54]. Before group members can effectively work together they often need to have a better understanding of each other, an understanding that may be best developed through media with social presence.

P8: Newly formed groups, groups with new members, and groups without accepted norms for production, group well-being, or member support will require more use of media with high synchronicity (high feedback and low parallelism).

P9: Newly formed groups, groups with new members, and groups without accepted norms will engage in more socially related communication activities than established groups and thus prefer the use of media providing symbols sets with greater social presence.

\section{Conclusion}

Media richness theory argues that task performance will be improved when capabilities of the media (cues, feedback, personal focus, and language variety) are matched to task equivocality and uncertainty. Media richness theory has strong face validity, but empirical evidence has provided only mixed support. In this paper, we defined five media capabilities that subsume and extend the original four dimensions of media richness theory: immediacy of feedback, parallelism, symbol variety, reprocessability, and rehearsability. Based on an analysis of these dimensions, we concluded that face-to-face communication is not always the "richest" medium for communication. The "best" medium or set of media depends upon which of these five dimensions are most important for a given situation. As different instantiations of a medium can provide more or less of these capabilities (e.g., an e-mail system from one vendor may provide high symbol variety while that 
of another may provide only low symbol variety), we argued that attempting to classify the relative "richness" of media in general is not worthwhile.

We believe that the key to effective use of media is to match media capabilities to the fundamental communication processes required to perform the task. Because most tasks require individuals to both convey information and converge on shared meanings, and media that excel at information conveyance are often not those that excel at convergence. Thus choosing one single medium for any task may prove less effective than choosing a medium or set of media which the group uses at different times in performing the task, depending on the current communication process (convey or converge). Media switching may be most appropriate.

Much research remains and it is unlikely for any one theory to explain all aspects of communication in the new media. Yet, we hope that this paper will stimulate new ideas and research to extend or refute our theory.

\section{References}

[1] Berlo, D.K. The Process of Communication. Holt, Rinehart and Winston, New York. 1960.

[2] Carnevale, P.J.D., Pruitt, D.G., and Seilheimer, S.D. "Looking and competing: Accountability and visual access in integrative bargaining," Journal of Personality and Social Psychology, 40:1, 1981, 111-120.

[3] Cherry, C. On Human Communication, MIT Press, Cambridge MA. 1978.

[4] Clark, H.H. and Brennan, S.E., "Grounding in Communication," in Resnick, L.B., Levine, J.M, and Teasley, S.D. (eds.), Perspectives on Socially Shared Cognition, American Psychological Association, Washington DC, 1991, 127-149.

[5] Clark, H.H. and Wilkes Gibbs, D. "Referring as a Collaborative Process," Cognition, 22, 1986, 1-39.

[6] Daft, R.L., and Lengel, R.H. "Organizational information requirements, media richness and structural design," Management Science, 32:5, 1986, 554-571.

[7] Daft, R.L., Lengel, R.H., and Trevino, L.K. "Message equivocality, media selection and manager performance: Implications for information systems," MIS Quarterly, 11, 1987, 355-366.

[8] Daft, R.L., and Weick, K. "Toward a model of organizations as interpretation systems," Academy of Management Review, 9, 1984, 284-295.

[9] Daft, R.L., and Wiginton, J. "Language and Organization," Academy of Management Review, 4:2, 1979, 179-191.

[10] Dennis A.R. and Kinney, S.T. "Testing Media Richness Theory In The New Media: Cues, Feedback, and Task Equivocality," Information Systems Research, in press.

[11] El-Shinnawy, M.M., and Markus, M.L. "Media Richness Theory and New Communication Media: A Study of Voice Mail and Electronic Mail" Proceedings of ICIS, Dallas, TX, 1992, 91-105.

[12] Fulk, J., Steinfield, C.W., Schmitz, J., and Power, J.G. "A Social Information Processing Model of Media Use in Organizations" Communication Research, 1987, 529-552.
[13] Gersick, C.J.G. and Hackman, J.R. "Habitual Routines in Task-Performing Groups," Organizational Behavior and Human Decision Processes, 47, 1990, 65-97.

[14] Herzberg, F., B. Mausner, and B. Synderman, The Motivation to Work. New York, John Wiley, 1953.

[15] Hollingshead, A.B., McGrath, J.E., and O'Connor, K.M. "Group task performance and communication technology: A longitudinal study of computer-mediated vs face-to-face work groups," Small Group Research 24, 1993, 307-333.

[16] Huber, G.P. "A theory of the effects of advanced information technologies on organizational design," Academy of Management Review, 15:1, 1990, 47-71.

[17] Johansen, R., Vallee, J., and Spangler, K. Electronic meetings: Technological alternatives and social choices. New York: Academic Press, 1979.

[18] King, R.C., Hartman, A., and Hartzel, K. "Message Creation Versatility, Media Capacity, and Media Choice: A Forward Looking Perspective," Proceedings of ICIS, Dallas, TX, 1992, 257.

[19] Kinney, S.T, and Watson, R.T. "The Effect of Medium and Task on Dyadic Communication," Proceedings of ICIS, Dallas, TX, 1992, 107-117.

[20] Kraus, R.M. and Bricker, P.D. "Effects of Transmission Delay and Access Delay on the Efficiency of Verbal Communication," Journal of the Acoustical Society, 41, 1966, 286-292.

[21] Kraus, R.M. and Weinheimer, S. "Concurrent Feedback, Confirmation, and the Encoding of Referents in Verbal Communication," Journal of Personality and Social Psychology, 4, 1966, 343-346.

[22] Kraut, R.E., Lewis, S.H. and Sweezy, L.W. "Listener Responsiveness and the Coordination of Conversation," Journal of Personality and Social Psychology, 43, 1982, 718-731.

[23] Leavitt, H.J. and Mueller, R.A. "Some Effects of Feedback on Communication," Human Relations, 4, 1951, 401-410.

[24] Lee, A.S. "Electronic mail as a medium for rich communication: An empirical investigation using hermeneutic interpretation," MIS Quarterly, 1994 143-157.

[25] Lengel, R., and Daft, R. "The selection of communication media as an executive skill," Academy of Management Executive, 2, 1988, 225-232.

[26] Littlejohn, S.W. Theories of Human Communication, Belmont, CA, Wadsworth Publishing. 1983.

[27] Malone, T.W., and Crowston, K. "The interdisciplinary study of coordination," ACM Computing Surveys, 26(1), 1994, 87-119.

[28] Markus, M.L. "Toward a "critical mass" theory of interactive media," Communication Research, 14, 1987, 491-511.

[29] Markus, M.L. "Electronic mail as medium of managerial choice," Organization Science, 5 1994, 502-527.

[30] McGrath, J.E. Groups: Interaction and Performance, Englewood Cliffs, N,: Prentice-Hall, Inc. 1984.

[31] McGrath, J. "Time matters in groups," In J. Galegher, R.E. Kraut, and C. Egido (Eds.), Intellectual teamwork: Social and technical bases of collaborative work Hillsdale, NJ, Erlbaum. 1990, 23-61.

[32] McGrath, J.E. "Time, interaction, and performance (TIP): A theory of groups" Small Group Res., 22 1991, 147-174. 
[33] McGrath, J.E. "Introduction: The JEMCO workshop: Description of a longitudinal study," Small Group Research, 24, 1993, 285-306.

[34] McGrath, J.E., and Hollingshead, A.B. "Putting the "group" back in group support systems: Some theoretical issues about dynamic processes in groups with technological enhancements," In Group Support Systems: New Perspectives, L.M. Jessup and J.S. Valacich (eds), New York, Macmillan, 1993, 78-96.

[35] McGrath, J.E., and Hollingshead, A.B. Groups Interacting with Technology, Newbury Park, CA, Sage, 1994.

[36] Mennecke, B.E., Hoffer, J.A., and Wynne, B.E. "The implications of group development and group history for GSS theory and practice," Small Group Research, 23, 1992, 524-572.

[37] Moscovici, S. "Toward a Theory of Conversion Behavior," in L. Berkowitz (ed.), Advances in Experimental Social Psychology, 13, New York: Academic Press, 1980, 209-239.

[38] Nunamaker Jr., J.F., Dennis, A.R., Valacich, J.S., Vogel, D.R., and George, J.F., "Electronic meeting systems to support group work" Communications of the ACM, 34:7, 1991, 40-61.

[39] Ngwenyama, O.K. and Lee, A.S. "Communication Richness In Electronic Mail: Critical Social Theory and Contextuality of Meaning," MIS Quarterly, 1997, 145-167.

[40] Petty, R.E. and Cacioppo, J.T. Communication and Persuasion, New York, Springer-Verlag, 1986.

[41] Rana, A.R., Turoff, M., and Hiltz, S.R. "Task and Technology Interaction (TTI): A Theory of Technological Support for Group Tasks," HICSS, 1997, II: 66-75.

[42] Random House Random House Dictionary of the English Language, 2nd ed, New York, Random House, 1987.

[43] Rapoport, A. "The promise and pitfalls of information theory," Behavioral Science, 1, 1956, 303-309.

[44] Reinsch, N. L., and Beswick, R. W., "Voice mail versus conventional channels: A cost minimization analysis of individuals' preferences," Academy of Management Journal, 33, 1990, 801-816.

[45] Rice, R. "Computer-mediated communication and organizational innovation," Journal of Communication, 37:4, 1987, 65-94.

[46] Rice, R.E. "Task analyzability, use of new media, and effectiveness: A multi-site exploration of media richness," Organization Science, 3:4, 1992, 475-500.

[47] Rice, R.E. "Media appropriateness: Using social presence theory to compare traditional and new organizational media," Human Communication Research, 20(2), 1993.

[48] Rice, R.E., and Aydin, C. "Attitudes toward new organizational technology: Network proximity as a mechanism for social information processing," Administrative Science Quarterly, 36, 1991, 219-244.

[49] Rice, R.E., Grant, A., Schmitz, J., Torobin, J. "Individual and network influences on the adoption and perceived outcomes of electronic messaging," Social Networks, 12:1, 1990, 27-55.

[50] Rice, R.E., and Shook, D. "Relationships of job categories and organizational levels to use of communication channels, including electronic mail: A meta-analysis and extension," Journal of Management Studies, 27:2, 1990, 195-229.
[51] Rice, R.E., and Steinfield, C. "Experiences with new forms of organizational communication via electronic mail and voice messaging," In J.H. Andriessen and R. Roe (Eds.) Telematics and work, London, Lawrence Erlbaum and Associates, 1993.

[52] Schmitz, J., and Fulk, J. "Organizational colleagues, media richness, and electronic mail," Communication Research, 18:4, 1991, 487-523.

[53] Shannon, C.E. and Weaver, W. The mathematical theory of communication, Urbana, University of Illinois, 1949.

[54] Shaw, M. Group Dynamics, 3rd edition, New York, McGraw Hill. 1981

[55] Short, J., Williams, E., and Christie, B. The Social Psychology of Telecommunications, New York Wiley 1976

[56] Sproull, R.F. "A lesson in electronic mail," In L. Sproull and Sara Kiesler, Connections: New Ways of Working in the Networked Organization, Cambridge, MA: MIT Press, 1991, 177-184.

[57] Sproull, L., and Kiesler, S. "Reducing Social Context Cues: Electronic Mail in Organizational Communication," Management Science, 32, 1986, 1492-1512.

[58] Trevino, L.K., Lengel, R.H., and Daft, R.L. "Media symbolism, media richness, and media choice in organizations," Communication Research, 1987, 553-574

[59] Trevino, L.K., Lengel, R.H., Bodensteiner, W., Gerloff, E., and Muir, N.K. "The richness imperative and cognitive style: The role of individual differences in media choice behavior," Management Communication Quarterly, 4, 1990, 176-197.

[60] Tuckman, B. "Development Sequence in Small Groups," Psychological Bulletin, 63, 1965, 384-399.

[61] Valacich, J.S., Mennecke, B.E., Wachter, R., and Wheeler, B.C. "Extensions to media richness theory: A test of the task-media fit hypothesis," Proceedings of HICSS, 1994, IV:11-20.

[62] Valacich, J.S., Paranka, D., George J.F., and Nunamaker Jr., J.F. "Communication Parallelism and the New Media: A New Dimension for Media Richness," Communication Research, 20:2, 1993, 249-276.

[63] Van de Ven, A.H., and Delbecq, A. "The effectiveness of nominal, Delphi, and interacting group decision making," Academy of Management Journal, 17, 1974, 605-621.

[64] Weick, K.E. "Cosmos vs. Chaos: Sense and nonsense in electronic contexts," Organizational Dynamics 1985 51-64.

[65] Weick, K.E., and Meader, D.K. "Sensemaking and group support systems," In L.M. Jessup and J.S. Valacich (Eds.), Group Support Systems: New Perspectives, New York, Macmillan, 1993, 230-252,

[66] Walther, J.B. "Interpersonal Effects in ComputerMediated Interaction," Communication Research, 19, 1992, $52-90$.

[67] Walther, J.B. "Anticipated Ongoing Interaction Versus Channel Effects on Relational Communication in Computer-Mediated Interaction," Human Communication Research, 20, 1994, 473-501.

[68] Williams, E. "Experimental comparisons of face-to-face and mediated communication: A review," Psychological Bulletin, 84:5, 1977, 963-976.

[69] Zmud, R.W., Lind M.R., and Young, F.W. "An attribute space for organizational communication channels," Information Systems Research, 1:4, 1990, 440-457. 